\title{
Comparison of coronary artery bypass grafting and percutaneous coronary intervention in patients with heart failure with reduced ejection fraction and multivessel coronary artery disease
}

\author{
Michał Hawranek ${ }^{1}$, Michal O. Zembala ${ }^{2}$, Mariusz Gasior ${ }^{1}$, Tomasz Hrapkowicz², \\ Łukasz Pyka ${ }^{1}$, Daniel Cieśla ${ }^{3}$ and Marian Zembala ${ }^{2}$ \\ 13rd Department of Cardiology, School of Medicine with the Division of Dentistry in Zabrze, Medical University of Silesia, \\ Katowice, Silesian Centre for Heart Disease, Zabrze, Poland \\ ${ }^{2}$ Department of Cardiac, Vascular and Endovascular Surgery and Transplantology, School of Medicine with the Division of \\ Dentistry in Zabrze, Medical University of Silesia in Katowice, Silesian Center for Heart Diseases, Zabrze, Poland \\ ${ }^{3}$ Department of Science, Biostatistics and New Technologies, Silesian Centre for Heart Disease, Zabrze, Poland \\ Correspondence to: Michał Hawranek, email: mhawranek@poczta.fm
}

Keywords: chronic heart failure; ischemic cardiomyopathy; percutaneous coronary interventions; coronary artery bypass grafting; revascularization

Received: October 16, $2017 \quad$ Accepted: March 01, $2018 \quad$ Published: April 20, 2018

Copyright: Hawranek et al. This is an open-access article distributed under the terms of the Creative Commons Attribution License 3.0 (CC BY 3.0), which permits unrestricted use, distribution, and reproduction in any medium, provided the original author and source are credited.

\section{ABSTRACT}

Aims: To compare coronary artery bypass grafting (CABG) with percutaneous coronary interventions (PCI) in patients with heart failure with reduced ejection fraction (HFrEF) and multivessel coronary artery disease.

Methods: 1213 patients were selected from institutional databases, 761 and 452 in CABG and PCI group respectively. Only the subjects with left ventricle ejection fraction $\leq 35 \%$ and multivessel coronary artery disease were included to the study. The primary outcome measure was long-term all-cause death, the secondary outcomes were recurrent myocardial infarction, urgent repeat revascularization and stroke. Propensity Score-Based Adjusted Survival Curves were used for revascularization methods comparison.

Results: Survival rates were similar in both groups (HR, 0.91; 95\% CI, 0.65-1.28; $p=0.59$ ). Recurrent myocardial infarction was observed significantly less often in the CABG group (HR, 0.44; 95\% CI, 0.26-0.74; $\mathrm{p}=0.002$ ). Repeat urgent revascularization was less frequent in the CABG group ( $\mathrm{HR}, 0.50 ; 95 \% \mathrm{CI}, 0.30-0.84 ; \mathrm{p}=0.008)$. The rate of stroke did not differ between the groups (HR, 1.17; 95\% CI, 0.62-2.22; $p=0.62$ ).

Conclusions: In patients with HFrEF and multivessel CAD revascularization both with CABG and PCI resulted in similar survival rates. PCI is associated with increased risk of recurrent MI and urgent repeat revascularization, whereas the risk of stroke is similar in both methods.

\section{INTRODUCTION}

The estimated population incidence of heart failure (HF) in the developed countries ranges from $1 \%$ to $2 \%$ and at least one-half have heart failure with reduced ejection fraction (HFrEF) $[1,2]$. Coronary artery disease (CAD) is the most common etiology for HFrEF and has increased with the growing incidence of associated mortality [2]. This unfavorable prognosis is related to progressive nature of ischemic left ventricle (LV) dysfunction and concomitant comorbidities, such as chronic kidney disease or diabetes.

Guideline-directed medical therapy remains the most important option and is associated with undisputed benefit in survival and quality of life [2]. Revascularization 
may have an additive positive effect on prognosis [3]. In the recent guidelines on myocardial revascularization, coronary artery bypass grafting $(\mathrm{CABG})$ has a class I recommendation, whereas percutaneous coronary interventions (PCI) only class IIb [4]. However, in everyday clinical practice many patients with $\mathrm{HFrEF}$ and multivessel CAD are treated with PCI. The advantage of CABG over $\mathrm{PCI}$ is based on the clinical trials comparing CABG with medical treatment, which reported survival benefit in this population of patients [5]. There are no such trials regarding PCI. Moreover, in last decades the only study dedicated to compare these two revascularization methods in $\mathrm{HFrEF}$ population was finished prematurely [6].

Additionally, trials comparing CABG vs PCI in stable CAD rarely included patients with $\operatorname{HFrEF}[7,8]$. On the other hand, PCI in patients with HFrEF and CAD might be a reasonable alternative for surgical treatment. Decreased LVEF is one of the predictors of poor outcomes after CABG [9]. Moreover, HF patients have significant morbidity, which additionally increases the risk of intervention. Therefore, having at our disposal a large population of patients with HFrEF of ischemic etiology treated with either CABG or PCI, we aimed to compare these revascularization methods to assess their impact on prognosis.

\section{RESULTS}

Among 2730 patients in COMMIT-HF Registry and 15234 in ICSD, 1217 were finally included into analysis, 761 and 452 in the CABG and PCI group respectively (Figure 1). Most patients were excluded due to nonperformance of invasive diagnostics and therapy $(n=1143)$ and non-ischemic etiology of HF $(n=1027)$ in the PCI group. In the CABG patients, preserved LVEF $(n=13439)$ and nonisolated CABG $(n=986)$ were the most common exclusions.

Baseline characteristic is shown in Table 1. The PCI group had worse clinical profile with higher incidence of typical risk factors, prior ischemic events and prior revascularization procedures. New York Heart Association (NYHA) class III and IV were observed more frequently in this group of patients. The mean LV ejection fraction was significantly lower in the PCI group. These differences were reflected in the Euroscore II risk scale, which was significantly higher in patients treated with PCI.

All the patients included into analysis had at least two major coronary arteries diseased with higher prevalence of 3-vessel disease in the CABG group. Moreover, left main (LM) disease, left coronary artery disease and chronic total occlusion occurrence were found more often in this group. These data confirm more complex atherosclerosis in surgically treated patients. Angiographic and procedural characteristics are shown in Table 2. All the patients treated with CABG had at least one arterial graft, typically left internal mammary artery to the left anterior descending artery (86.7\%). During
PCI procedures, drug eluting stents (DES) were used more frequently than bare metal stents (BMS). Complete anatomical revascularization was achieved significantly more often in the CABG group. A detailed analysis of patients treated with CABG or PCI with DES only is provided in the Supplementary Materials. (Supplementary Tables 1-3 and Supplementary Figures 6-9).

\section{Short-term outcomes}

In hospital, 30-day and 1-year outcomes were shown in Table 3. There were no differences in the prognosis besides the higher incidence of myocardial infarction (MI) in the PCI group at one year. The rate of stroke was low within the first 30 days after the procedure even in the surgical group with similar percentage in both groups after 1 year.

\section{Long-term outcomes}

The primary outcome measure was all-cause longterm rate of death. Kaplan-Meier curves are presented in Figure 2. Death occurred less often in the CABG patients (HR, 0.71; 95\% CI, 0.55-0.92; $\mathrm{p}=0.008$ ), however after adjustment for clinical and angiographic differences, survival rates were similar in both groups (HR, 0.91; 95\% CI, 0.65-1.28; $\mathrm{p}=0.59$ ). Results of secondary outcomes are shown in Figure 3. Recurrent MI was observed significantly less often in the CABG group (HR, 0.44; $95 \%$ CI, $0.26-0.74 ; p=0.002$ ). More than $50 \%$ of the events occurred within the first year after index procedure. Similarly, repeat urgent revascularization was less frequent in the $\mathrm{CABG}$ group regardless of the adjustment (HR, $0.50 ; 95 \%$ CI, $0.30-0.84 ; p=0.008)$. The rate of stroke did not differ between the groups, with early hazard of the events observed in the surgically treated patients (HR, $1.17 ; 95 \%$ CI, 0.62-2.22; $\mathrm{p}=0.62$ ). Detailed results of multivariate regression analysis for primary and secondary outcomes measures are provided in the supplementary materials together with Kaplan-Meier curves for the risk of death adjusted for EuroSCORE 2 scale components. (Supplementary Figures 1-5).

\section{DISCUSSION}

The study presents a comparison of long-term outcomes of CABG and PCI in patients with multivessel CAD and HFrEF. The main findings are as follows: (1) the patients treated with PCI had worse clinical profile, whereas the surgical patients had more advanced atherosclerosis; (2) long-term survival rates were similar in both groups; (3) PCI was associated with increased risk of recurrent $\mathrm{MI}$ and urgent repeat revascularization in long-term observation.

$\mathrm{CAD}$ is the etiologic factor of two-thirds of all systolic HF cases and its treatment poses a significant 
challenge [10]. Even though revascularization has been shown to improve the prognosis, data on specific therapeutic strategies is scarce and mostly related to CABG [3]. In part, it is a consequence of former studies demonstrating a survival benefit of CABG over medical treatment in patients with reduced LVEF and multivessel disease [6]. There was no such comparison for PCI. However, PCI has been shown to exceed the number of $\mathrm{CABG}$ in this population, even despite the lack of compelling data from contemporary randomized studies $[4,11,12]$. This was also confirmed in our prior analysis [13]. Although reduced LVEF should guide the patient toward surgery, it seems that together with excessive morbidity it reduces the chance of CABG performance. Both significantly increase the risk of open heart surgery. On the other hand, patients with ischemic etiology of HF usually present high atherosclerosis burden in the coronary arteries. It is confirmed that in patients with advanced atherosclerosis reflected in high Syntax Score, survival benefit from CABG in comparison to PCI is more distinct and such patients should be treated surgically [7]. Results of our analysis were consistent with these observations. Patients treated with PCI had higher incidence of typical risk factors, prior ischemic events and more pronounced HF symptoms, while patients qualified for CABG had more complex atherosclerosis with higher occurrence of LM stenosis, triple-vessel disease and chronic total occlusions. Moreover, in the analyzed population, the overall frequency of neoplastic disease was higher in the PCI group. The presence of a neoplastic disease in CAD patients often drives the therapeutic decisions towards the less invasive modalities, to minimize the risks related to the cardiopulmonary bypass procedure [14]. Nonetheless, there were no significant differences between the study groups in the presence of history of malignant neoplasms. Additionally, complete revascularization was achieved more often in CABG patients, confirming that if surgery is possible, it offers more complex treatment.

There is scant evidence of PCI and CABG in HFrEF patients, because none of the completed revascularization randomized trials were focused on this population. Moreover, in the trials comparing these two revascularization strategies in stable conditions, patients with severe LV dysfunction where underrepresented or excluded [15]. In the recently published trials percentage of HFrEF patients was very low, $2 \%$ and $2.5 \%$ respectively, and it was also insufficient to reliably compare PCI and CABG in this population. $[7,8]$. In two previous, relatively large trials, patients with decreased LV ejection fraction represented $22 \%$ and $21 \%$ of the study population. In the subgroup analysis, there were no differences in outcome between both methods, but

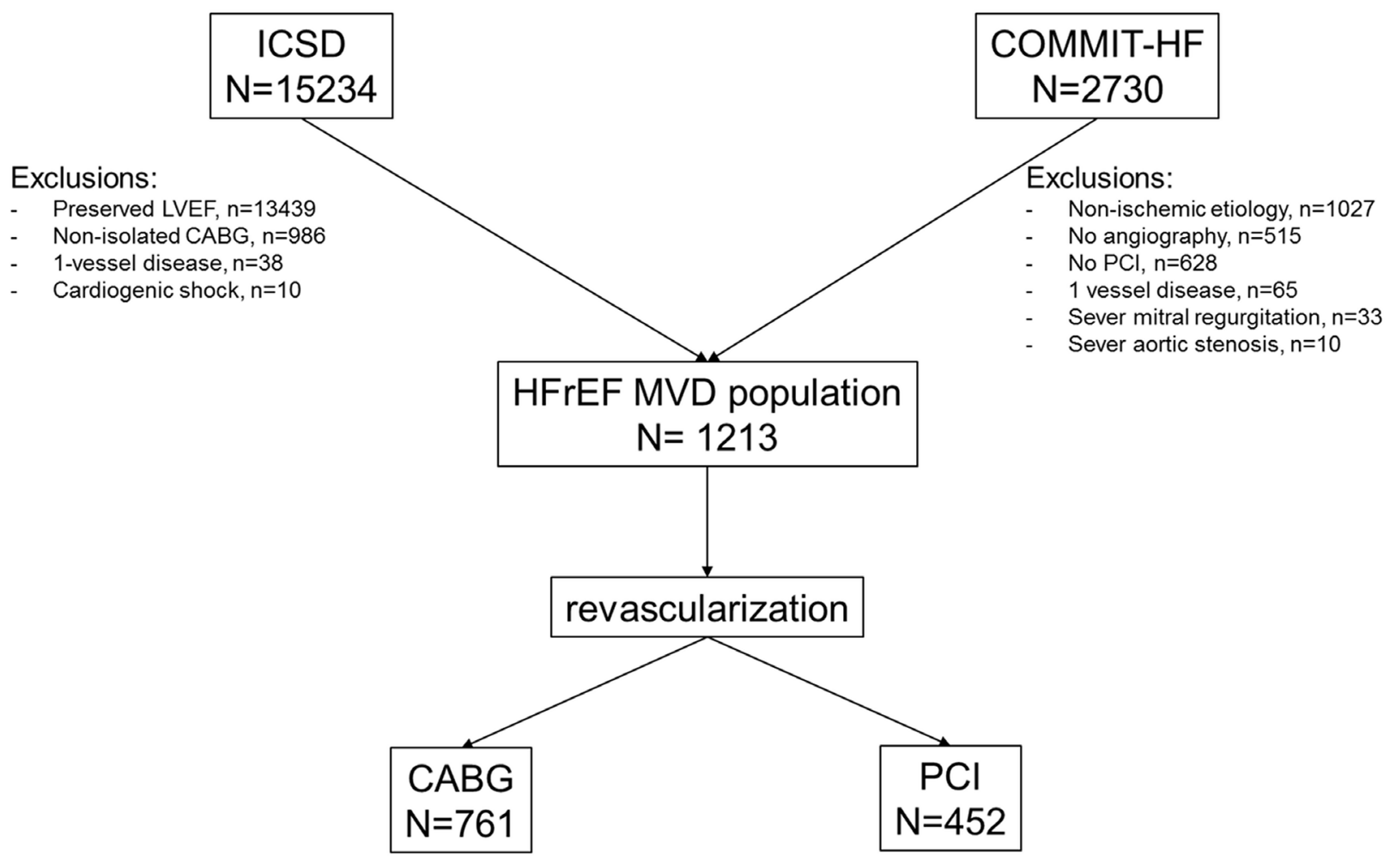

Figure 1: Study flow chart. MVD, multivessel coronary artery disease; COMMIT-HF, COnteMporary Modalities in Treatment of Heart Failure Registry; HFrEF, heart failure with reduced ejection fraction; ICSD, institutional cardiac surgery database; PCI, percutaneous coronary interventions; CABG, coronary artery bypass grafting; LVEF, left ventricle ejection fraction. 
Table 1: Baseline characteristics

\begin{tabular}{|c|c|c|c|}
\hline \multirow{2}{*}{ Factor } & Study population & $N=1213$ & \multirow{2}{*}{ P value } \\
\hline & CABG N = 761 & PCI $N=452$ & \\
\hline Age, years $\pm \mathrm{SD}$ & $64.7 \pm 9.0$ & $65.3 \pm 10.2$ & 0.32 \\
\hline Male, $\%$ & 82.5 & 84.1 & 0.54 \\
\hline $\mathrm{BMI}, \mathrm{kg} / \mathrm{m}^{2} \pm \mathrm{SD}$ & $27.7 \pm 4.4$ & $28.3 \pm 4.4$ & 0.07 \\
\hline Arterial hypertension, \% & 79.2 & 63.1 & $<0.001$ \\
\hline Prior one MI, \% & 54.9 & 53.5 & 0.68 \\
\hline Prior two or more MI, $\%$ & 20.6 & 30.1 & $<0.001$ \\
\hline Prior PCI, \% & 37.6 & 62.8 & $<0.001$ \\
\hline Prior $\mathrm{CABG}, \%$ & 0.5 & 20.6 & $<0.001$ \\
\hline Atrial fibrillation, $\%$ & 11.6 & 23.0 & $<0.001$ \\
\hline Prior stroke, $\%$ & 9.1 & 7.3 & 0.33 \\
\hline Diabetes mellitus, \% & 37.3 & 47.8 & $<0.001$ \\
\hline Dyslipidemia, \% & 62.0 & 48.0 & $<0.001$ \\
\hline COPD, $\%$ & 13.4 & 10.0 & 0.09 \\
\hline Neoplastic disease, $\%$ & 16.5 & 22.0 & 0.03 \\
\hline Malignant neoplasms, \% & 9.5 & 12.2 & 0.18 \\
\hline Benign neoplasms, $\%$ & 7.0 & 9.7 & 0.14 \\
\hline \multicolumn{4}{|l|}{ NYHA Class $*$} \\
\hline $\mathrm{I}, \%$ & 21.3 & 16.6 & 0.06 \\
\hline II, $\%$ & 59.9 & 38.3 & $<0.001$ \\
\hline III, \% & 17.1 & 36.3 & $<0.001$ \\
\hline $\mathrm{IV}, \%$ & 1.7 & 8.9 & $<0.001$ \\
\hline eGFR ${ }^{*}, 30-60 \mathrm{ml} / \mathrm{min} / 1.73 \mathrm{~m}^{2}, \%$ & 11.3 & 12.6 & 0.55 \\
\hline $\mathrm{eGFR}^{*},<30 \mathrm{ml} / \mathrm{min} / 1.73 \mathrm{~m}^{2}, \%$ & 7.4 & 10.4 & 0.08 \\
\hline $\mathrm{LVEF}^{*}, \% \pm \mathrm{SD}$ & $30.9 \pm 4.5$ & $27.4 \pm 5.5$ & $<0.001$ \\
\hline EUROSCORE 2 scale, \% & $3.64 \pm 4.36$ & $4.49 \pm 4.86$ & 0.001 \\
\hline
\end{tabular}

BMI, body mass index; CABG, coronary artery bypass grafting; CAD, coronary artery disease; COPD, chronic obstructive pulmonary disease; eGFR = estimated glomerular filtration rate; LVEF, left ventricular ejection fraction; MI, myocardial infarction; NYHA, New York Heart Association; PCI, percutaneous coronary intervention; Q1-Q3, quartile 1 and quartile 3; $\mathrm{SD}$, standard deviation.

PCI was performed with either balloon angioplasty or bare-metal stents and these analyses combined together consisted of less than 500 patients $[16,17]$. Therefore, we must turn for guidance at observational studies. However, their heterogeneity makes them difficult to interpret. In two recent registries focused on $\mathrm{HFrEF}$ patients, only the minority of the patients had truly reduced $\operatorname{LVEF}[11,18]$. These data are difficult to extrapolate to the HF population with severely impaired LVEF. A direct comparison of PCI and CABG in the ischemic heart failure population was published recently by Bangalore et al., comparing 1063 matched pairs of patients treated either with PCI with everolimuseluting stents or CABG. Overall rates of long-term allcause mortality were similar in both groups. In the PCI group there were fewer strokes, but more myocardial 
Table 2: Angiographic and procedural characteristics

\begin{tabular}{lccc}
\hline \multirow{2}{*}{ Factor } & Study population & $\mathbf{N}=\mathbf{1 2 1 3}$ & P value \\
\cline { 2 - 4 } & CABG N = 761 & PCI N = 42 & $<0.001$ \\
\hline 2-vessel disease, \% & 24.8 & 48.0 & $<0.001$ \\
3-vessel disease, \% & 75.2 & 52.0 & $<0.001$ \\
Territory & & & $<0.001$ \\
LM, \% & 38.5 & 13.3 & $<0.001$ \\
LAD/D1, \% & 99.5 & 91.8 & 0.1 \\
Cx/OM/IM, \% & 91.7 & 80.1 & $<0.001$ \\
RCA/PDA, \% & 84.0 & 80.1 & $<0.001$ \\
CTO, \% & 56.5 & 39.6 & \\
CTO, mean \pm SD & $0.85 \pm 0.91$ & $0.51 \pm 0.73$ & \\
No of grafts, mean \pm SD & $2.50 \pm 0.93$ & & \\
- Arterial grafts, mean \pm SD & $1.01 \pm 0.50$ & & \\
- Saphenous grafts, mean \pm SD & $1.49 \pm 0.97$ & $1.75 \pm 1.06$ & \\
No of stents, mean \pm SD & & $1.29 \pm 1.19$ & \\
- DES, mean \pm SD & & $0.47 \pm 0.90$ & \\
- BMS, mean \pm SD & 68.6 & 54.0 & \\
Complete revascularization, \% & & & \\
\hline
\end{tabular}

BMS, bare metal stents; CABG, coronary artery bypass grafting; CTO, chronic total occlusion; $\mathrm{Cx}$, circumflex artery; D1, first diagonal branch; DES, drug eluting stents; IM, intermediate branch; LAD, left anterior descending; LM, lef t main; $\mathrm{OM}$, obtus marginal branch; PDA, posterior descending artery; PCI, percutaneous coronary intervention; RCA, right coronary artery; SD, standard deviation.

Table 3: In-hospital, 30 day and 1 year outcomes

\begin{tabular}{|c|c|c|c|}
\hline \multirow{2}{*}{ Factor } & Study population & $N=1213$ & \multirow{2}{*}{ P value } \\
\hline & CABG N $=761$ & PCI $N=452$ & \\
\hline \multicolumn{4}{|l|}{ In-hospital } \\
\hline death, $\%$ & 1.6 & 0.9 & 0.45 \\
\hline MI, \% & 0.9 & 1.3 & 0.7 \\
\hline stroke, $\%$ & 0.8 & 0.4 & 0.72 \\
\hline \multicolumn{4}{|l|}{30 day } \\
\hline Death, \% & 3.0 & 2.4 & 0.67 \\
\hline MI, \% & 1.5 & 2.2 & 0.45 \\
\hline Stroke, $\%$ & 1.1 & 0.4 & 0.42 \\
\hline \multicolumn{4}{|l|}{1 year } \\
\hline Death, $\%$ & 9.7 & 10.2 & 0.87 \\
\hline MI, \% & 2.0 & 5.9 & 0.002 \\
\hline Stoke, \% & 2.3 & 2.5 & 0.97 \\
\hline
\end{tabular}

Abbreviations: $\mathrm{CABG}$, coronary artery bypass grafting; MI, myocardial infarction; PCI, percutaneus coronary intervention. 
infarctions and repeat revascularizations over a median follow-up of 2.9 years [19]. Although these results came from a large registry, there were some major exclusion criteria: LM disease, prior cardiac surgery, prior PCI. In our analysis, patients with prior cardiac surgery and/ or prior percutaneous revascularization constituted one-third and two-thirds of patients in CABG and PCI arm respectively. Moreover, LM disease was found in $38 \%$ of CABG patients and in $13 \%$ of PCI patients. Therefore, almost half of our population would not have been included in the abovementioned analysis. This is probably the first report analyzing a wide HFrEF population almost without exclusions.

A diminishing mortality gap between $\mathrm{CABG}$ and PCI may be partially explained by the technological progress in interventional cardiology. New-generation thin-strut DES and additional devices allow for more complex interventions in more complex anatomy. Alongside improvements in the devices themselves, use of fractional flow reserve for functional revascularization, intravascular imaging for stenting deployment, periprocedural LV support in very highrisk subgroups or more potent antiplatelet drugs may ultimately influence the results. On the other hand, surgery addresses not only the current lesion, but also the disease that might progress and become a culprit in the future. In may be of importance in patients with HFrEF who will be less tolerant to repeated myocardial injury. In fact, in our population the risk of recurrent $\mathrm{MI}$ and urgent repeat revascularization was significantly higher in the PCI group.

In the present study, long-term survival after the adjustment for confounding factors was comparable for both revascularization strategies, while in the unadjusted population $\mathrm{CABG}$ offered significant reduction in mortality. Risk adjustment contains both clinical and angiographic parameters. This initial difference can be partly explained by worse clinical status and comorbidities among patients treated with PCI and more complex revascularization in the $\mathrm{CABG}$ patients.

These results come from an observational study and are only hypothesis-generating. However, for several years ischemic heart failure has been one of the major challenges in cardiovascular medicine and randomized trials in this field are still missing. The HFrEF population poses a substantial challenge in diagnosis and treatment. The majority of patients have multiple disorders, multifocal advanced atherosclerosis and numerous prior revascularization procedures. HF by itself is treated with sophisticated pharmacotherapy, comorbidities additionally increase the drug interaction. A possible combination of various factors creates an almost infinite number of clinical variants which should be addressed. One may speculate that attempts to perform a randomized clinical trial comparing CABG and PCI in HFrEF could be hampered by the inclusion criteria bias. Nowadays, all the available data should be incorporated to assist the decision-making process in routine clinical practice. In fact, very often a decision on revascularization in ischemic HF cannot be made solely based on current guidelines. A personalized approach towards every patient is mandatory, and therefore the role of the Heart Failure Team in this process is vital.

\section{Limitations}

There are several limitations of our analysis. Firstly, due to observational design of the study, despite the use of advanced adjustment methods, potential selection biases could occur. Multivariate model analysis may also

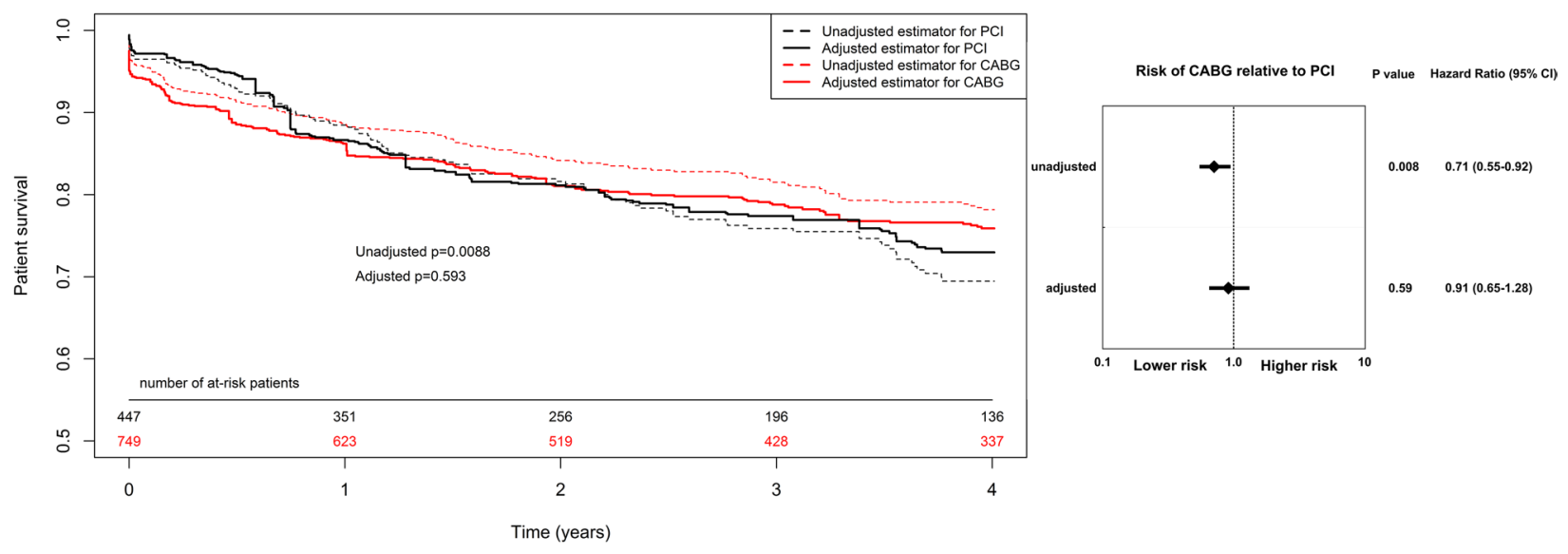

Figure 2: Kaplan-Meier curves and Forest plot for long term all-cause death. CABG, coronary artery bypass grafting; CI, confidential interval; HR, hazard ratio PCI, percutaneous coronary interventions. Results adjusted for: sex, age, diabetes mellitus, hypertension, New York Heart Association classification at admission, Left Ventricle Ejection Fraction, previous stroke, previous transient ischaemic attack, chronic obstructive pulmonary disease, atrial fibrillation, chronic kidney disease, previous PCI, left main disease, twoand three vessel coronary artery disease. 
be biased because of a potential effect of confounding predictors that were not accessible. Secondly, we did not have data on anatomic SYNTAX risk score. Thirdly, in the PCI arm, the patients were treated both with BMS and DES, while DES are a gold standard now. Moreover, we did not assess cardiovascular mortality that may be of importance in this population.
A

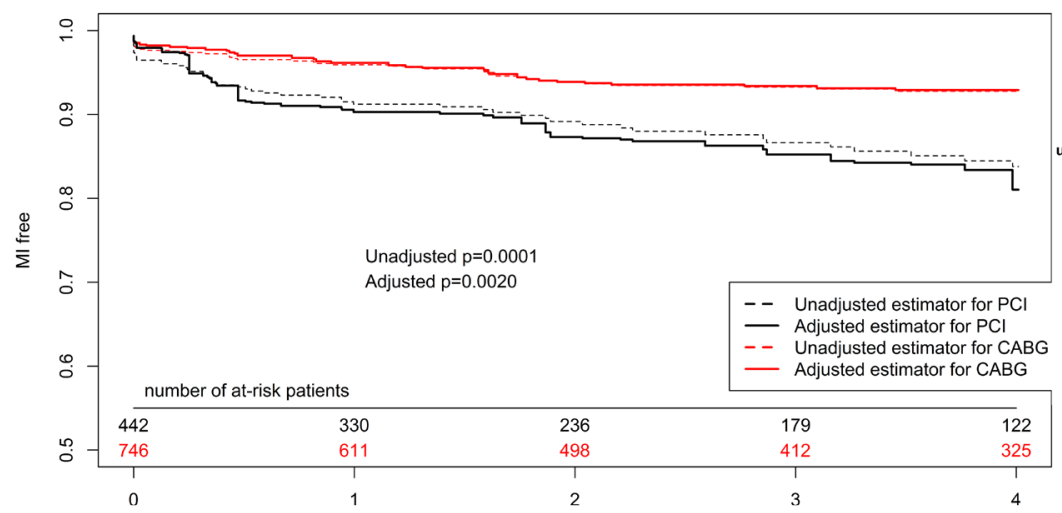

B

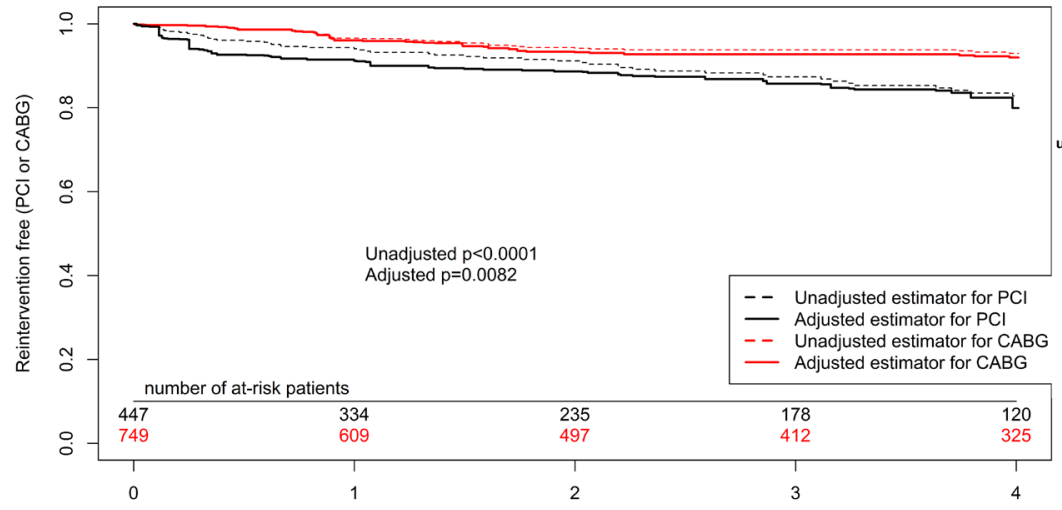

C

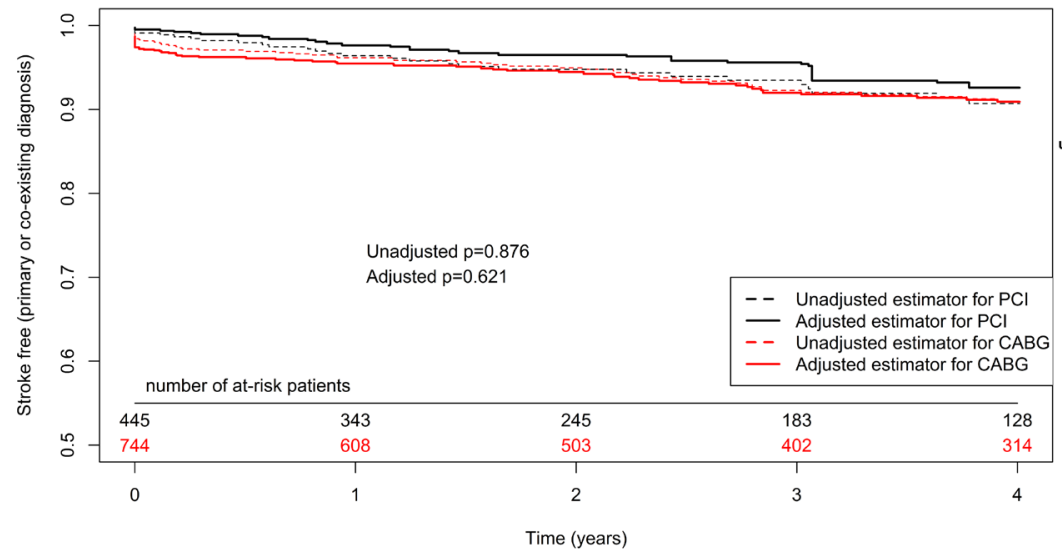

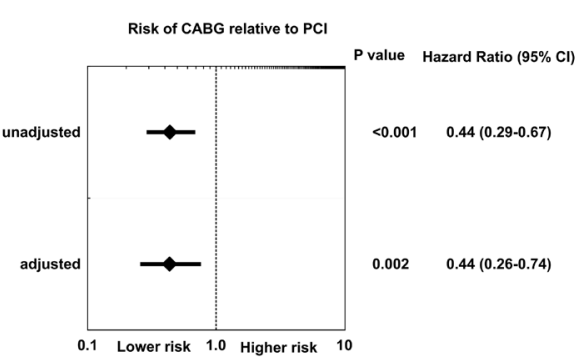
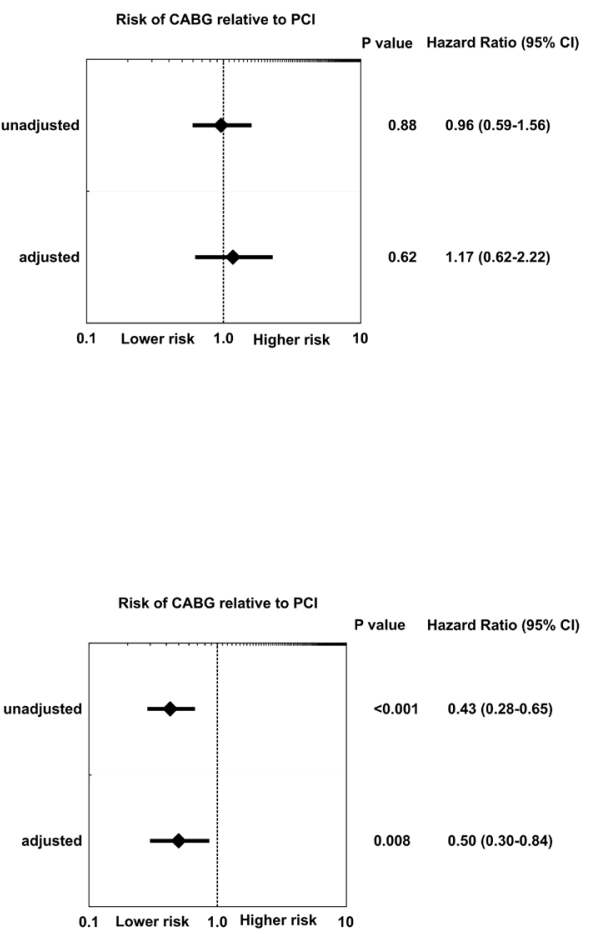

Figure 3: Kaplan-Meier curves and Forest plot for long term secondary outcomes (A, myocardial infarction; B, urgent revascularization; C, stroke). CABG, coronary artery bypass grafting; CI, confidential interval; HR, hazard ratio PCI, percutaneous coronary interventions. Results adjusted for: year of intervention, male sex, age, diabetes mellitus, hypertension, New York Heart Association classification at admission, left ventricle ejection fraction, previous stroke, previous transient ischaemic attack, chronic obstructive pulmonary disease, atrial fibrillation, chronic kidney disease, previous PCI, left main disease, two- and three vessel coronary artery disease. 


\section{MATERIALS AND METHODS}

\section{Patients selection}

The patients were selected from the COMMIT-HF (COnteMporary Modalities in Treatment of Heart Failure) Registry and the Institutional Cardiac Surgery Database (ICSD). The COMMIT-HF registry has been described elsewhere [13]. In brief, it is a prospective ongoing registry of an all-comer systolic heart failure patient population $(\mathrm{LVEF}<=35 \%)$ treated in the Third Chair and Department of Cardiology since 2009. The ICSD is the institutional registry of cardiac surgery operations and covers all the procedures performed in the Silesian Center for Heart Diseases since 2006., Only the patients with confirmed multivessel CAD defined as severe stenosis $(>=70 \%)$ in at least 2 major epicardial arteries or stenosis $(\geq 50 \%)$ of the left main (LM) and severely reduced ejection fraction $(\mathrm{LVEF} \leq 35 \%)$, who underwent $\mathrm{PCI}$ or $\mathrm{CABG}$ were included into the analysis. Only the patients with stage $\mathrm{C}$ or $\mathrm{D}$ according to $\mathrm{ACCF} / \mathrm{AHA}$ chronic heart failure classification were included into the analysis [20]. The patients with concomitant severe mitral valve regurgitation or severe aortic valve stenosis, myocardial infarction within 5 days preceding the index procedure, unstable hemodynamics or who were in cardiogenic shock, were excluded from the study. In both registries, LV ejection fraction was assessed by transthoracic echocardiography before the index procedure. Study design is shown in Figure 1. In the clinical characteristics, the presence of neoplastic disease has been analyzed based on the ICD-10 classification. Patients with $\mathrm{C}$ category at any time before revascularization were identified as having malignant neoplastic disease. This study has been granted permission from the Institutional Review Board and is consistent with the ethical standards laid down in the 1964 Declaration of Helsinki and its amendments.

\section{Interventions}

Unfractionated heparin under the control of activated clotting time as well as P2Y12 inhibitor were administered to the patients undergoing coronary angioplasty. Balloon predilatation and postdilatation, the use of stents, type of stents, glycoprotein IIb/IIIa receptor inhibitors and others established interventional techniques were at the operator's discretion. In case of CABG, a decision on the extent and type of the procedure (classical CABG, off-pump CABG or minimally invasive direct coronary artery bypass) has been initially taken by the Heart Team and, if necessary, changed by the operators. In both groups, the treatment was performed with the intention to achieve complete revascularization (CR). For this analysis, an anatomic definition of $\mathrm{CR}$ was used. CR was defined as successful PCI of all angiographically significant lesions in all coronary arteries with a diameter of at least $2 \mathrm{~mm}$, without a patent surgical graft in the PCI group, and grafting of all coronary arteries with a diameter of at least $2 \mathrm{~mm}$ and angiographically significant stenosis in the $\mathrm{CABG}$ group.

\section{Follow up}

Both in-hospital and long-term follow-up were obtained in all the patients. In-hospital data came from the institutional electronic database which covered all clinical, angiographic, laboratory records and the history of hospitalization. All the adverse events were verified with source documentation. Data on patients from both registries were linked with the national health care provider database which covers all the hospitalizations and performed procedures after discharge. Data on mortality was obtained from the same source [21].

\section{Outcomes}

Both short-term (30 days) and long-term prognoses were evaluated. The primary outcome of the study was long-term all-cause death. The secondary outcomes were myocardial infarction (MI), stroke and urgent repeat revascularization. Non-fatal MI was defined as an ischemic event that met the European Society of Cardiology/American College of Cardiology/American Heart Association criteria for myocardial infarction [22]. Repeat urgent revascularization was defined as an unplanned PCI or CABG, performed as urgent procedure due to acute ischemic symptoms. Stroke was defined as an ischemic event that is in accordance with European Stroke Organization guidelines [23].

\section{Statistical analysis}

Variables were presented in tables containing the arithmetic mean with standard deviation for quantitative and frequency for qualitative parameters. Distribution of quantitative variables was tested by the Shapiro-Wilk test. Due to other than normal distributions, the verification of hypothesis of the parameters equality in individual groups was performed by the Mann-Whitney U test. Distribution of qualitative variables was evaluated using the Chi-squared test. The Kaplan-Meier estimator and the Cox Proportional Hazards Model were used to analyze long-term absolute survival and event-free survival. In order to assess the effect of the performed treatment on the outcome, a univariate model was calculated for each endpoint, containing only the information about the type of performed treatment. In the next step, the multivariable model containing parameters from baseline characteristics was generated.

Because of the differences in baseline characteristics of the analyzed groups, Propensity Score Based Adjusted Survival Curves were used [24]. Propensity score was calculated for the same variables used in Cox's multivariate 
analysis - the dependent variable was the mode of treatment. All the hypotheses were assumed as two-tailedverified by two-tailed tests. For the purposes of the analysis, p-value $<0.05$ was considered as statistically significant. The R version 3.3.3 (2017-03-06) The R Foundation for Statistical Computing was used for all the calculations.

\section{CONCLUSIONS}

Among the patients with HFrEF and multivessel coronary artery disease, similar rates of survival in the patients treated with either PCI or CABG were noted. PCI was associated with an increased risk of recurrent MI and urgent repeat revascularization, whereas the risk of stroke was similar for both methods. The results are hypothesis-generating and should be tested in prospective, randomized trials.

\section{Abbreviations}

CABG: coronary artery bypass grafting; CAD: coronary artery disease; $\mathrm{CI}$ : confidence interval; $\mathrm{CR}$ : complete revascularization; HF: heart failure; HFrEF: heart failure with reduced ejection fraction; HR: hazard ratio; ICD-10 - International Statistical Classification of Diseases and Related Health Problems; LM: left main; LV: left ventricle; LVEF: left ventricle ejection fraction; MI: myocardial infarction; PCI: percutaneous coronary intervention.

\section{Author contributions}

All authors have read and approved the manuscript and have contributed sufficiently to warrant authorship, which includes the following: 1: conception and design or analysis and interpretation of data, or both $(\mathrm{MH}, \mathrm{MOZ}$, LP, DC, MG), 2: drafting of the manuscript or revising it critically for intellectual content $(\mathrm{MH}, \mathrm{MOZ}, \mathrm{MG}, \mathrm{TH}$, LP, MZ), 3: final approval of the manuscript submitted (all authors). There is agreement to be accountable for all aspects of the work to ensure that any questions related to the accuracy or integrity of any part of the work are appropriately investigated and resolved.

\section{CONFLICTS OF INTEREST}

The authors have no conflicts of interest to declare.

\section{REFERENCES}

1. Ambrosy AP, Fonarow GC, Butler J, Chioncel O, Greene SJ, Vaduganathan M, Nodari S, Lam CS, Sato N, Shah AN, Gheorghiade M. The global health and economic burden of hospitalizations for heart failure: lessons learned from HHF registries. J Am Coll Cardiol. 2014; 63:1123-33. https://doi. org/10.1016/j.jacc.2013.11.053.
2. Ponikowski P, Voors AA, Anker SD, Bueno H, Cleland JG, Coats AJ, Falk V, González-Juanatey JR, Harjola VP, Jankowska EA, Jessup M, Linde C, Nihoyannopoulos P, et al, and ESC Scientific Document Group. 2016 ESC Guidelines for the diagnosis and treatment of acute and chronic heart failure: the Task Force for the diagnosis and treatment of acute and chronic heart failure of the European Society of Cardiology (ESC)Developed with the special contribution of the Heart Failure Association (HFA) of the ESC. Eur Heart J. 2016; 37:2129-200. https://doi. org/10.1093/eurheartj/ehw128.

3. Velazquez EJ, Lee KL, Deja MA, Jain A, Sopko G, Marchenko A, Ali IS, Pohost G, Gradinac S, Abraham WT, Yii M, Prabhakaran D, Szwed H, et al, and STICH Investigators. Coronary-artery bypass surgery in patients with left ventricular dysfunction. N Engl J Med. 2011; 364:1607-16. https://doi.org/10.1056/NEJMoa1100356.

4. Windecker S, Kolh P, Alfonso F, Collet JP, Cremer J, Falk V, Filippatos G, Hamm C, Head SJ, Jüni P, Kappetein AP, Kastrati A, Knuuti J, et al, and Authors/ Task Force members. 2014 ESC/EACTS Guidelines on myocardial revascularization: The Task Force on Myocardial Revascularization of the European Society of Cardiology (ESC) and the European Association for CardioThoracic Surgery (EACTS)Developed with the special contribution of the European Association of Percutaneous Cardiovascular Interventions (EAPCI). Eur Heart J. 2014; 35:2541-619. https://doi.org/10.1093/eurheartj/ehu278.

5. Alderman EL, Fisher LD, Litwin P, Kaiser GC, Myers WO, Maynard C, Levine F, Schloss M. Results of coronary artery surgery in patients with poor left ventricular function (CASS). Circulation. 1983; 68:785-95. https://doi. org/10.1161/01.CIR.68.4.785.

6. Cleland JG, Calvert M, Freemantle N, Arrow Y, Ball SG, Bonser RS, Chattopadhyay S, Norell MS, Pennell DJ, Senior R. The Heart Failure Revascularisation Trial (HEART). Eur J Heart Fail. 2011; 13:227-33. https://doi. org/10.1093/eurjhf/hfq230.

7. Serruys P, Morice M, Kappetein A, Colombo A, Holmes D, Mack MJ, Stahle E, Feldman TE, van den Brand M, Bass EJ, Van Dyck N, Leadley K, Dawkins KD, Mohr FW. Syntax Investigators. Percutaneous coronary intervention versus coronary-artery bypass graft- ing for severe coronary artery disease. N Engl J Med. 2009; 360:961-72. https://doi. org/10.1056/NEJMoa0804626.

8. Farkouh ME, Domanski M, Sleeper LA, Siami FS, Dangas G, Mack M, Yang M, Cohen DJ, Rosenberg Y, Solomon SD, Desai AS, Gersh BJ, Magnuson EA, et al, and FREEDOM Trial Investigators. Strategies for multivessel revascularization in patients with diabetes. $\mathrm{N}$ Engl J Med. 2012; 367:2375-84. https://doi.org/10.1056/ NEJMoa1211585.

9. Nashef SA, Roques F, Sharples LD, Nilsson J, Smith C, Goldstone AR, Lockowandt U, Euroscore II. EuroSCORE 
II. Eur J Cardiothorac Surg. 2012; 41:734-44. https://doi. org/10.1093/ejcts/ezs043.

10. Bui AL, Horwich TB, Fonarow GC. Epidemiology and risk profile of heart failure. Nat Rev Cardiol. 2011; 8:30-41. https://doi.org/10.1038/nrcardio.2010.165.

11. Marui A, Kimura T, Nishiwaki N, Komiya T, Hanyu M, Shiomi H, Tanaka S, Sakata R. Three-year outcomes after percutaneous coronary intervention and coronary artery bypass grafting in patients with heart failure: from the CREDO-Kyoto percutaneous coronary intervention/ coronary artery bypass graft registry cohort-2. Eur J Cardiothorac Sur. 2015; 47:316-21.

12. Nieminen MS, Brutsaert D, Dickstein K, Drexler H, Follath F, Harjola VP, Hochadel M, Komajda M, Lassus J, LopezSendon JL, Ponikowski P, Tavazzi L, and EuroHeart Survey Investigators, and Heart Failure Association, European Society of Cardiology. EuroHeart Failure Survey II (EHFS II): a survey on hospitalized acute heart failure patients: description of population. Eur Heart J. 2006; 27:2725-36. https://doi.org/10.1093/eurheartj/ehl193.

13. Gasior M, Pyka L, Gorol J, Hawranek M, Tajstra M, Słonka G, Kurek A, Krajewski A, Rozentryt P, Gierlotka M, Lekston A, Zembala M, Poloński L. COnteMporary Modalities In Treatment of Heart Failure: report from the COMMIT-HF Registry. Kardiol Pol. 2016; 74:523-28.

14. Pinto CA, Marcella S, August DA, Holland B, Kostis JB, Demissie K. Cardiopulmonary bypass has a modest association with cancer progression: a retrospective cohort study. BMC Cancer. 2013; 13:519. https://doi. org/10.1186/1471-2407-13-519.

15. Velazquez EJ, Bonow RO. Revascularization in severe left ventricular dysfunction. J Am Coll Cardiol. 2015; 65:61524. https://doi.org/10.1016/j.jacc.2014.10.070.

16. Berger PB, Velianou JL, Aslanidou Vlachos H, Feit F, Jacobs AK, Faxon DP, Attubato M, Keller N, Stadius ML, Weiner BH, Williams DO, Detre KM, and BARI Investigators. Survival following coronary angioplasty versus coronary artery bypass surgery in anatomic subsets in which coronary artery bypass surgery improves survival compared with medical therapy. Results from the Bypass Angioplasty Revascularization Investigation (BARI). J Am Coll Cardiol. 2001; 38:1440-49. https://doi.org/10.1016/ S0735-1097(01)01571-6.

17. Sedlis SP, Ramanathan KB, Morrison DA, Sethi G, Sacks J, Henderson W, and Department of Veterans Affairs Cooperative Study \#385, Angina With Extremely Serious Operative Mortality Evaluation (AWESOME) Investigators. Outcome of percutaneous coronary intervention versus coronary bypass grafting for patients with low left ventricular ejection fractions, unstable angina pectoris, and risk factors for adverse outcomes with bypass (the AWESOME Randomized Trial and Registry). Am J Cardiol. 2004; 94:118-20. https://doi.org/10.1016/j. amjcard.2004.03.041.

18. Tsuyuki RT, Shrive FM, Galbraith PD, Knudtson ML, Graham MM, and APPROACH Investigators. Revascularization in patients with heart failure. CMAJ. 2006; 175:361-65. https://doi.org/10.1503/cmaj.060108.

19. Bangalore S, Guo Y, Samadashvili Z, Blecker S, Hannan EL. Revascularization in patients with multivessel coronary artery disease and severe left ventricular systolic dysfunction. Everolimus-elutig stents versus coronary artery bypass graft surgery. Circulation. 2016; 133:2132-40. https://doi.org/10.1161/CIRCULATIONAHA.115.021168.

20. Yancy CW, Jessup M, Bozkurt B, Butler J, Casey DE Jr, Drazner MH, Fonarow GC, Geraci SA, Horwich T, Januzzi JL, Johnson MR, Kasper EK, Levy WC, et al, and American College of Cardiology Foundation/American Heart Association Task Force on Practice Guidelines. 2013 ACCF/AHA guideline for the management of heart failure: a report of the American College of Cardiology Foundation/ American Heart Association Task Force on practice guidelines. Circulation. 2013; 128:e240-327. https://doi. org/10.1161/CIR.0b013e31829e8807.

21. Gąsior M, Pres D, Wojakowski W, Buszman P, Kalarus Z, Hawranek M, Gierlotka M, Lekston A, Mizia-Stec K, Zembala M, Poloński L, Tendera M. Causes of hospitalization and prognosis in patients with cardiovascular diseases. Secular trends in the years 2006-2014 according to the SILesian CARDiovascular (SILCARD) database. Pol Arch Med Wewn. 2016; 126:754-62.

22. Thygesen K, Alpert JS, White HD, Jaffe AS, Apple FS, Galvani M, Katus HA, Newby LK, Ravkilde J, Chaitman B, Clemmensen PM, Dellborg M, Hod H, et al, and Joint ESC/ACCF/AHA/WHF Task Force for the Redefinition of Myocardial Infarction. Universal definition of myocardial infarction. Eur Heart J. 2007; 28:2525-38. https://doi. org/10.1093/eurheartj/ehm355.

23. European Stroke Organisation (ESO) Executive CommitteeESO Writing Committee. Guidelines for management of ischaemic stroke and transient ischaemic attack 2008. Cerebrovasc Dis. 2008; 25:457-507. https:// doi.org/10.1159/000131083.

24. Xie J, Liu C. Adjusted Kaplan-Meier estimator and logrank test with inverse probability of treatment weighting for survival data. Stat Med. 2005; 24:3089-110. https://doi. org/10.1002/sim. 2174 . 